\title{
Aproximación al conflicto y oportunidad de las migraciones
}

\section{Approach to conflict and opportunity of migration}

\author{
Jahir Alexander Gutiérrez, Ossa \\ Economista por la Universidad de Medellín, Colombia; (PhD) en Administración Pública, Atlantic International \\ University - AIU, Honolulú, USA; magister en Desarrollo por la Universidad Pontificia Bolivariana, Medellín, \\ Colombia; estudios en especialización de Sistemas de Información Geográfica, Universidad San Buenaventura - USB, \\ Medellín, Colombia; investigador de la Facultad de Ciencias Administrativas y Económicas del Tecnológico \\ de Antioquia, Colombia. \\ Correo electrónico: jagogutierrez@gmail.com. \\ Gleidy Alexandra Urrego Estrada \\ Magíster en Hábitat por la Universidad Nacional de Colombia; administradora pública por la Escuela Superior de \\ Administración Pública - ESAP. Miembro del grupo de investigación Observatorio Público, Institución Universitaria \\ Tecnológico de Antioquia, Colombia. \\ Correo electrónico:gleidy.urrego@gmail.com
}

\section{Resumen}

El presente artículo tiene como objetivo la aproximación al contexto de la migración con referencia al estado de conflicto y oportunidad que crea para los migrantes y los países receptores dicho proceso. La metodología empleada fue descriptiva con dos fases: revisión bibliográfica y aplicabilidad de dicha revisión. Como conclusiones principales se abordó que en la actualidad, la migración se ha convertido en proceso de tensión internacional, ha provocado amplias disertaciones y no se ha llegado a estimar el estado de balance equilibrado que pueda contribuir a superar el debate. Además, es importante iniciar un proceso de diálogo y revisión, en aras de consolidar política pública, que claramente atienda esta población, en el ámbito nacional como el internacional.

Palabras clave: Conflictos, oportunidades, migraciones.

\section{Abstract}

This article aims to approach the context of migration with reference to the state of conflict and creates opportunity for migrant and recipient countries that process. The methodology used was descriptive, with two phases: literature review and applicability of the review. The main conclusions are addressed that at present, the migration process has become of international tension, has caused extensive lectures and has not reached balanced estimate the state of balance that can contribute to overcoming the debate. Furthermore, it is important to begin a process of dialogue and review, in order to consolidate public policy that clearly treats this population, nationally and internationally.

Keywords: Conflicts, opportunities, migration.

\section{Résumé}

Cet article vise à aborder le contexte de la migration en référence à l'état de conflit et crée des opportunités pour les pays de migrants et bénéficiaires de ce processus. La méthodologie utilisée était descriptive, avec deux phases: revue de la littérature et de l'applicabilité de l'examen. Les principales conclusions sont abordées aujourd'hui, la migration est devenue un processus de tension internationale, a causé de vastes cours et n'a pas atteint l'estimation équilibrée de l'état d'équilibre qui peut contribuer à surmonter le débat. En outre, il est important de commencer un processus de dialogue et d'examen, afin de consolider la politique publique qui traite clairement cette population, à l'échelle nationale et internationale.

Mots-clés: les conflits, les opportunités, les migrations

Recibido: 20 de mayo de 2016. Aprobado: 16 de julio de 2016 



\title{
Aproximación al conflicto y oportunidad de las migraciones
}

\author{
Approach to conflict and opportunity of migration*
}

Jahir Alexander Gutiérrez Ossa

Gleidy Alexandra Urrego Estrada

\section{INTRODUCCIÓN}

El presente artículo tiene como objetivo la aproximación al contexto de la migración con referencia al estado de conflicto y oportunidad que crea para los migrantes y los países receptores dicho proceso. En tanto, la mirada hacia la inmigración tomó visos de irritabilidad internacional, cuando dicha población comenzó a ser vinculada a los múltiples fallos ocasionados en el modelo económico reinante y la política económica de cada país receptor, pasando ellos a representar, parte de las dificultades que comenzarían a tener los países mencionados en diversos campos.

El derrumbe paulatino de las principales economías del mundo y con ellas de su política laboral, sirvieron de polvareda para quienes en silencio rechazaban la presencia foránea desde cualquier denominación, tomando con ello, las riendas, la dirección y el pensamiento para satirizar la inmigración como el hecho latente que en parte había erosionado las bases en que estaban apoyados los principios de los países receptores (Désirée, 2006).

Los conflictos sociales asociados con el tema de la inmigración hacen referencia a varios ámbitos de la realidad social. Algunos se desenvuelven alrededor de aspectos legales, políticos o sociales como, por ejemplo, en situaciones de competencia por los servicios sociales entre la población inmigrante y la población autóctona. Hay otros

Este artículo presenta resultados preliminares del proyecto de investigación en curso: "Evaluación Geoestratégica del Departamento del Chocó en el Marco de las Trampas del Subdesarrollo: El G-8 AID para el Departamento del Chocó. Financiado por la Dirección de Investigaciones de la Institución Universitaria Tecnológico de Antioquia, ejecutado por el grupo de investigación Observatorio Público (OpcionTdeA) registrado en Colciencias, durante el periodo de septiembre de 2014 a septiembre 2015. 
conflictos en el ámbito cultural sobre las posibilidades y los modos de desarrollo de los inmigrantes o sobre la actitud de la mayoría frente a las minorías y a la diversidad cultural del país.

Una a una fueron apareciendo diversas manifestaciones representadas por organizaciones internas -en los países receptores- y externas en los -países emisores-de población migrante para encauzar los patrones sobre los cuales debería en adelante entenderse el análisis y racionalidad sobre la población migrante. En principio, la discusión se centró en velar por las condiciones y los derechos humanos de la población migrante, puesto que los temas económicos y políticos, debido al velo económico que representaba la bonanza económica y financiera global, no alcanzaba para que estos tópicos fueran mezclados (Cárdenas y Mejía, 2006).

En las últimas décadas, las migraciones internacionales han adquirido una importancia creciente en la agenda política y económica mundial. Muestra de ello son las multitudinarias marchas en las principales ciudades de los Estados Unidos a comienzos de 2006, así como la intensa discusión que suscitó el Proyecto de Ley de Inmigración en ese país. Adicionalmente, se está reviviendo el importante debate sobre las condiciones de vida de los emigrantes de los países en desarrollo, como Colombia, en los países receptores de estos flujos. De otro modo, cómo se verá más adelante, fue hace poco que la emigración de colombianos adquirió magnitudes importantes. Por esta razón, no es extraño que las migraciones internacionales no sean un tema central de la literatura especializada en Colombia.

La metodología empleada se basa en el enfoque descriptivo. Su diseño considera dos fases: i) revisión bibliográfica e informes relacionados con categorías como migraciones, conflictos y oportunidades migratorias y ii) análisis de la aplicabilidad de los contenidos bibliográficos. Como antecedentes se considera la arremetida de los Estados desarrollados en contra de los movimientos y procesos migratorios de forma categórica y directa. Además, se ha puesto el tema al frente de las prioridades de discusión por parte de los países expulsores y receptores a la par con los organismos internacionales, quienes velan por mejorar las condiciones de dicha población. Contrario a ello, el nacionalismo acérrimo campea como medida para paliar a la fuerza está situación que para los países receptores tiende a convertirse en un fenómeno y no en un proceso de movimiento demográfico que no amenaza la seguridad nacional, sino que atiende aspectos positivos que ha traído en varios casos la población inmigrante.

El entramado en que ha sido apoyada la idea de combatir la migración en sus distintas modalidades, incluyendo las que terminan siendo protegidas por salvedades normativas o principios de derecho internacional, tienen alerta a los promotores de crear controles y medidas para detener el creciente ascenso de la población foránea. Además, de los que están en contra de las medidas represivas, por considerarlas por fuera de todo propósito de respeto por la dignidad humana, pues este proceso para ellos debe considerarse desde los derechos universales, sobre los cuales la migración debe ser apreciada como tal. 
A cada lado de los bandos se encuentra la población migrante, que en últimas, es quien tiene la posibilidad de determinar, además de las razones, las condiciones y probabilidades que ofrecen los países receptores para ser apreciados como bolsa de oportunidades. A su vez, con la que ellos y sus grupos familiares pueden tener un ingreso que represente para sí, la oportunidad de restablecer condiciones mínimas de vida, así sea a costa de aislar su condición de ciudadano o nacional, a la par con los derechos que terminan por desprenderse al momento de cruzar la frontera, cuya estancia no es definida.

Es importante para dar estructura a la migración, el reconocer la naturaleza de los principios y razones en que se apoya la población migrante para enfilar su vida hacia dicho propósito. Para ello, deben ser reconocidos los patrones de conducta que igualmente distinguen a esta población, que media a través de la condición de género para que el resultado de su escaramuza tenga algún asidero en el país receptor. La probabilidad de allanar espacios en donde puedan insertarse en escalada o fácilmente a los requerimientos económicos propios y claros está poder vislumbrar un mejor nivel de vida.

En la actualidad se ha generalizado la posición de conmoción y disputa para los líderes de países que hoy están al frente de las principales economías receptoras de migrantes. Si bien, antes se jactaban de ser apreciados cuna de oportunidades y modelo para seguir, en el presente, su preocupación está sobre las condiciones y el estatus que debe tener la población migrante. Hacia ella, la tendencia es vincularla al eje de problemáticas que hoy enfrentan los países receptores. De paso, los países emisores deben ponerse alerta de la situación, por el efecto boomerang de esta circunstancia, que puede desvanecer lo logrado en materia de impactos de la migración en sus economías.

El artículo está compuesto por los siguientes parámetros de análisis: En primer lugar, una revisión general de la migración como un proceso revestido de diferentes matices, que requieren de una contemplación más abierta y pública, que la prescripción del estatus y la discriminación legal. En segunda instancia, abordaje que tiene la población migrante en diferentes escenarios. Finalmente, se realiza una aproximación al proceso migratorio en Colombia.

\section{LA MIGRACIÓN COMO PROCESO DE CONFLICTO Y OPORTUNIDAD}

El desenvolvimiento en que se ha venido caracterizando la migración ha servido para notificar en gran medida los nexos que compartimentan las relaciones internacionales entre las naciones. Si bien, los principios de igualdad dignidad que debe gozar el ciudadano migrante, ha sido entre otros, un llamado por el respeto a los pueblos y a las razones que sobre el tema esgrime el derecho internacional con respecto a este sujeto, en la actualidad, la realidad ha demostrado que la apreciación, además del trato recibido por este sujeto es distante de los preceptos que dieron origen a los movimientos migratorios (Rodríguez, 2008). 
Las migraciones han sido una necesidad para la humanidad desde la antigüedad, cuando el hombre se desplazaba de un lugar a otro en busca de medios de subsistencia o para eludir a enemigos humanos o naturales, recorriendo de esta forma el planeta. Históricamente, las migraciones han cambiado por completo el aspecto de los países, influyendo en su composición social, lingüística y cultural. De hecho, la sociedad de los próximos años va a ser más heterogénea y mosaica.

Las motivaciones que acompañaban al proceso migratorio eran más que sobreentendidas por parte de los países receptores, que no siempre compaginaban con la perspectiva general de su población. Sin embargo, las consecuencias de la Segunda Guerra Mundial instó para que las banderas xenofóbicas o de otra índole declinarán, dando paso a la posibilidad para que la población migrante tuviese oportunidad en los países receptores; considerada una forma deliberada de contribuir al crecimiento y desarrollo económico de los pueblos. Toda vez que, para la mayoría era comprensible la llegada de estos a otras latitudes, en busca de oportunidades, entremezcladas por las fuerzas económicas y las doctrinas políticas (Sprandel y otros, 2008).

Trataremos de los inmigrantes en ese sentido más estricto del término, pese a que la diferencia entre refugiado e inmigrante en el panorama actual no siempre es muy evidente. Por una parte, el deterioro de las condiciones económicas en el país de origen del inmigrante es tan acentuada que parece ingenuo considerar a la inmigración como una elección; tanto es así que algunos autores han pasado incluso a usar el término "refugiado económico". Por otra parte, muchas veces, los candidatos al refugio terminan por engrosar el flujo de migrantes internacionales, puesto que es cada vez más difícil obtener el reconocimiento oficial como refugiado, y encontrar países dispuestos a ofrecer cobijo.

Algunas formas de agresión abiertamente manifiestas, que connotaron la migración como un concepto sensible, para quienes institucional y legislativamente exigían un trato recio a la conducción y manejo de la política migratoria, fueron amainadas desde diversas explicaciones. Incluso, se reconvino a los promotores de las políticas represivas, a replantear su posición frente a la condición e impacto al igual que ante el estatus y origen de la población inmigrante. Esto es, después de haber definido su estancia en el país receptor, tendrían la necesidad de adaptar sus costumbres a las prerrogativas del país receptor y claro está con ello, a aceptar la institucionalidad, que con el tiempo arrojaría resultados positivos para el país, por lo que representaría para la economía y el desarrollo (Solanes, 2002).

La universalidad de los derechos humanos, su garantía y reconocimiento con carácter general son totalmente incompatibles con las políticas sobre extranjería e inmigración que reduce a su mínima expresión tales derechos o incluso, en el caso de los inmigrantes irregulares, mantienen su negación como principio. Se insiste en colocar al extranjero inmigrante en una posición inferior sin entrar a plantear que esta es una situación anómala que no debe perpetuarse.

De condición de inmigrante pasarían a la condición de ciudadano inmigrante, con crecientes oportunidades en diversos campos, que se traducirían igualmente en una 
apuesta para aquellos que observaban y estimaban el éxito de los primeros migrantes, como una especie de camino que ellos debían igualmente tomar. A efectos de alcanzar sueños o cumplir las metas que para su terruño había considerado necesario, y que para él entonces, era sinónimo de éxito y prestancia, tanto para quienes se quedaban en el país de origen como al parecer para quienes "coronaban" la posibilidad de tener un lugar en el país receptor, independiente a la manera como llegaban, las expectativas superaban las probabilidades y los riesgos (Pesantez, 2006).

La incorporación de los factores sociales en el análisis de la migración permite considerar las redes como un elemento constitutivo de este proceso, a partir de una diversidad de enfoques teóricos como el de las comunidades transnacionales, las teorías de los sistemas y la de la causación acumulativa, mencionadas en este artículo de forma general.

El aparente estado de promoción al que había sido estimada la migración, sirvió para que se presentaran en los países receptores fieles escenarios de oportunidades para todo aquel que emprendiera su camino hacia dichas latitudes. Tal es así, que llegó a contemplarse como el "sueño americano o europeo", denotando con ello el estado de acción que impregnaba el hecho de que alguien sometiera al concurso de su vida, la posibilidad de alcanzar algún país que representará para sí los anhelos e intereses algo malogrados en el país de origen. De ahí, que el llamado para involucrarse fue un hecho general. Aprecia de nuevo (Rodríguez, 2008).

Muchas son las causas que motivan los movimientos de las poblaciones, siendo las consecuencias de los mismos de gran alcance y complejidad. Las migraciones son un proceso que afecta a un número considerable de individuos; se trata de un fenómeno que tiene tantas repercusiones tanto en el país de origen como en el de acogida.

El haber irrumpido en un sistema económico en cualquier campo sin pasar por un proceso sobre el cual pudiese medirse el impacto de la población inmigrante en las naciones receptoras, comenzaría a ser el artilugio para que la perspectiva en principio oculto tomara visos antisemitas y propagandísticos. Al respecto, empezaría toda una elaboración ideológica y política que respaldaría tal percepción con pensadores como Huntington, con la lucha de las civilizaciones entre otros, que abiertamente señalaron la condena en la que podían terminar los países, entre ellos, Estados Unidos, sino ponían fin a la inmigración (Velasco, 2006).

La creciente inadecuación del marco estatal para afrontar los retos globales que representan las migraciones se ponen de manifiesto de un modo especial a la luz de las nuevas características que estas ostentan en la actualidad y que resultan difíciles de gestionar por los Estados particulares.

Argumentos de toda naturaleza sirvieron para justificar la posición radical frente al inmigrante, pasando por encima de los preceptos que acompañaron el nacimiento de organismos como la ONU, en cuanto al marco de protección y recibo que deberían tener cualquier inmigrante o población por parte del país receptor. Frente a ello, las voces de protesta no se hicieron esperar y bajo argumentos igualmente sólidos, 
justificaron por su parte las razones en que se demostraba la trascendencia que había tenido la población inmigrante para la cultura, la economía, la política, la religión y la sociedad de los países receptores, siendo precisamente estos preceptores la razón de la disputa (Mora, 2010).

A pesar de las actitudes negativas hacia la inmigración que se extienden por Europa y de las escasas simpatías que estos movimientos sociales suelen despertar entre la mayor parte de la opinión pública, parece evidente que la fuerza e intensidad de sus acciones y reivindicaciones no va a decaer en los próximos años.

La irrupción cultural era claramente distante entre los inmigrantes y la población del país receptor. De ahí que, muchos de ellos comenzarían a formar colonias o cordones de pobladores, provenientes del mismo origen o en su defecto de la misma parte del continente, como una especie de refugio paralelo ante la arremetida de derecha. A su vez, al conformar guetos o poblaciones del mismo origen, comenzarían entre ellos a desarrollar actividades para su propia supervivencia sobre lo cual el patrón contractual se moverían en la misma población, hechos que sirvieron para avanzar en materia de interés político, cuyo beneficio se traduciría en la búsqueda del reconocimiento de status. Amplían Gómez y otros:

A partir del momento en que las migraciones fueron percibidas como un fenómeno mundial como consecuencia de la globalización, los esfuerzos para conseguir regular estos flujos crecientes por parte de los países receptores de inmigración se han orientado, por un lado, a la restricción del ingreso de nuevos inmigrantes y, por el otro, a la búsqueda de una forma de canalizar positivamente la oleada de trabajadores que se desplazan desde regiones de menor desarrollo hacia regiones más desarrolladas, en especial Europa y Estados Unidos (2010, p. 14).

La dirección dada al tema de la inmigración por parte de los países receptores al ser tema de seguridad nacional en los noventa, y no solo por la estrangulación económica junto a la mezcla cultural, serían los argumentos políticos que tomarían las autoridades de los países receptores. Así que, para tomar medidas por su cuenta, en una situación que ha terminado por medir el pulso político entre quienes lideran los intereses por proteger la soberanía de los estados y, quienes compulsan por establecer un compás de espera en la materia para que las medidas no causen más dificultades que las que se tratan de remediar (Azagra, 2010).

No debería ser la emigración un motivo de alarma para los países ricos. De atención sí, pero no de alarma. Nada hay en su impacto económico que justifique la flagrante contradicción que hay cuando se reclama al mismo tiempo libertad de movimiento de capitales y se restringe a las personas. Regular la entrada ilegal en los países no puede identificarse con elaborar normas criminalizadoras del inmigrante.

Es abiertamente conocida la polarización que ha consignado el tema por cualquiera de las miradas en las que descansa su justificación o rechazo. No obstante, existe un tercer actor del proceso que a la par con los mencionados, debe entrar para 
considerar la probabilidad de lo que puede significar la arremetida contra la población inmigrante. Son precisamente los países generadores de dicha población, que han adoptado una posición algo nihilista y pasiva para entrar a asumir la responsabilidad que como estados de unos nacionales sin ciudadanía, derechos o patria reclaman una identidad mundial (OIM 2006, 5):

Muchos países de destino han adoptado por fuerza de la costumbre actitudes restrictivas ante la inmigración, fundamentándose en que puede socavar la escala salarial local y las condiciones de trabajo, así como plantear problemas sociales y de seguridad. Sin embargo, los hechos demuestran que la migración apenas incide negativamente en los salarios y el empleo en los países de acogida. Además, no hay indicio alguno de la existencia de una correlación directa entre la migración y el desempleo. Se desconoce el cálculo final de la migración en el costo de la prestación de beneficios y servicios públicos, pero es demostrable su vinculación con la edad y la condición socioeconómica de los recién migrantes.

El reconocimiento de la identidad va de la mano con el estatus, pero no tratan de que esto sea remediado vía legislativa, sin consultar a las partes, o que por fuerza de las motivaciones más que por las razones de fondo que uno u otro lado puedan tener, no se llegará a contemplar lo ancho y profundo de la migración. Si bien, esta es la preocupación general, en ningún caso ha sido sometida a reflexión la condición de género, familia y de sujetos que ha traído con el paso de los años la explosión migratoria y la interacción entre ellos, hecho que aún no ha sido evaluado y, que podría generar más dificultades (Santos, 2009).

En pocas palabras, haciéndonos eco de una de las conclusiones del diálogo de alto nivel llevado a cabo hace tres años por las Naciones Unidas, las migraciones internacionales pueden tener un papel de primer orden en los esfuerzos de desarrollo, pero no son, en sí mismas, estrategias de desarrollo a largo plazo (ONU, 2006).

La condición de actor que reclama condiciones más dignas y humanas frente al estado de reflexión ideológico y técnico en que está siendo sopesada la discusión sobre inmigración, aún no ha sido contemplado como elemento central o por lo menos sustrato del tema, por encima de la connotación económica y política que ha recubierto la discusión. Esta situación implica que la migración debe ser analizada ampliamente como marco de política pública, tanto en los países receptores como emisores de dicha población (tabla 1), pues no se puede convertir en un tema de ruleta rusa o mampara política, para cuando no hayan más argumentos que la disputa pública con una población que al parecer ha aportado más de lo estimado. 
Tabla 1. Conflicto y oportunidades de las migraciones a escala de paises

\section{DIMENSIONES}

\begin{tabular}{|c|c|}
\hline & PAÍS RECEPTOR \\
\hline Política & $\begin{array}{l}\text { - Aumento del gasto público para ga- } \\
\text { rantizar funcionamiento de servicios } \\
\text { sociales y de seguridad. } \\
\text { - Demanda de infraestructura urbana, } \\
\text { a través de políticas de planificación } \\
\text { del territorio (disponibilidad de suelo } \\
\text { para vivienda con condiciones de ha- } \\
\text { bitabilidad, espacio público). }\end{array}$ \\
\hline Económica & $\begin{array}{l}\text { - Demanda de generación de empleo } \\
\text { - Políticas económicas de empleo } \\
\text { cerradas y que favorezca exclusiva- } \\
\text { mente a los nacionales. }\end{array}$ \\
\hline Social & $\begin{array}{l}\text { - Inseguridad } \\
\text { - Demanda de un entorno ambiental- } \\
\text { mente saludable } \\
\text { - Demanda de salud, educación y polí- } \\
\text { ticas culturales. }\end{array}$ \\
\hline Cultural & $\begin{array}{l}\text { - Choques culturales de identidad y } \\
\text { costumbres (pérdida de identidad } \\
\text { cultural y costumbres) } \\
\text { - Sentimientos de pérdida e incerti- } \\
\text { dumbre. }\end{array}$ \\
\hline & PAÍS EMISOR \\
\hline Política & - Pérdida del electorado \\
\hline Económica & $\begin{array}{l}\text { - Aumento de la inflación local } \\
\text { - Pérdida de mano de obra (fuerza pro- } \\
\text { ductiva) } \\
\text { - Urbanización sin planificación y } \\
\text { reglamentación. (Vivienda con con- } \\
\text { diciones de habitabilidad y espacio } \\
\text { público). }\end{array}$ \\
\hline
\end{tabular}

\section{OPORTUNIDAD}

- Participación electoral de migrantes en condición de residentes.

- Mano de obra (fuerza productiva)

- Aumento de las actividades económicas locales (crecimiento económico).

- Ciudades globales: Remesas sociales que llegan a los países de origen y fomentan los cambios culturales y sociales en estos, así como los nuevos conocimientos y dinámicas sociales que se emprenden en los países de destino como consecuencia de la interculturalidad.

- Apoyo a proyectos de infraestructura social, a través de las remesas económicas.

- Envío de remesas

- Oportunidades para la creación de negocios como microempresas, servicios, comercio, entre otros.

- Aumento en el consumo de la telefonía celular y servicios de internet. (Aumento del sector servicios). 
DIMENSIONES

\begin{tabular}{|c|c|c|}
\hline & $\begin{array}{l}\text { - Demanda de seguridad por extorcio- } \\
\text { nes por medio de amenazas, secues- } \\
\text { tros o daños. }\end{array}$ & \multirow{3}{*}{$\begin{array}{l}\text { - Ciudades globales: inter } \\
\text { cambio de conocimientos y } \\
\text { dinámicas sociales que se } \\
\text { emprenden en los países de } \\
\text { destino como consecuencia } \\
\text { de la interculturalidad. }\end{array}$} \\
\hline Social & $\begin{array}{l}\text { - Sentimientos de asilamiento, senti- } \\
\text { mientos de abandono y desintegra- } \\
\text { ción familiar. }\end{array}$ & \\
\hline Cultural & $\begin{array}{l}\text { - Choques culturales de identidad y } \\
\text { costumbres (pérdida de identidad } \\
\text { cultural y costumbres). }\end{array}$ & \\
\hline
\end{tabular}

Fuente: elaboración propia.

Por tanto, el complejo marco de reflexión sobre el que debe atenderse el proceso migratorio, obedece precisamente a la exacerbada posición que provoca, aunque en esencia carece de argumentos sobresalientes, más allá de la retórica sobre la sustracción de materia provocada por la población migrante. Esto no ha sido puesto en balanza cuando se trata de evaluar el impacto de la población en condición migrante en los países receptores. Sin embargo, continúa prosperando el vacío institucional con relación en la definición de un panorama claro y multilateral frente al trato que debe darse a esta población de doble vía, en tanto los países emisores como receptores de los migrantes.

\section{ESCENARIO DE LAS MIGRACIONES}

El proceso migratorio tuvo una época de apogeo relevante en los tiempos en que las economías, en medio de la crisis por recursos de materias primas, comenzarían a explorar otros campos económicos, sobre los cuales claro está la incursión en temas de tecnología. Nuevos hallazgos y conocimiento técnico irradiarán los preceptos convencionales de la relación capital-trabajo para aquel entonces, a mediados de los años setenta. Este nuevo impulso a la economía mundial, facilitado en parte por la entrada de países al concierto económico, provocaría una demanda simultánea de mano de obra calificada (Khoudour, 2007):

Cuanto más educada es la población, más tiende a emigrar a otros países. Las más calificadas están preparadas para enfrentar los retos de la migración, como dejar su entorno y vivir en un país con una cultura e idiomas diferentes. También le es más fácil informarse sobre las posibilidades de trabajo en el exterior y hacer los trámites para migrar. Por otra parte, en un contexto de políticas restrictivas, es menos difícil para un trabajador calificado obtener una visa para trabajar o estudiar en un país industrializado que para una persona menos calificada.

Otras actividades pasarían a ser apreciadas de menor valía, y cuyos incentivos para realizarlas, no eran compensatorios si se le comparase con las nuevas demandas 
y oferta salariales, traídas por cuenta de este giro económico global. La tecnificación de la industria basada en el conocimiento y la tecnología, y en la forma de concebir y dividir la calidad de la mano de obra (OEA, 2011).

Los inmigrantes están presentes en todos los sectores de la economía de los países de destino en mayor o menor grado, entre otras razones por la naturaleza cambiante de la actividad económica a causa de la competencia desde el exterior y a cambios estructurales en la economía, con la reasignación de recursos laborales hacia empresas y sectores de mayor productividad. La migración laboral puede ser un estímulo para el desarrollo de sectores de actividad creciente, con trabajadores con nuevas especializaciones contratados en el exterior, o también una manera para que las empresas se ajusten al mercado laboral o al cambio tecnológico, con trabajadores contratados para empleos que ya no son atractivos para los trabajadores locales, o en sectores cuya competitividad disminuye.

La división de trabajo acusada por estas circunstancias, abrió un boquete importante para que en los países en vías de desarrollo y emergentes fuese contemplada la posibilidad de que comenzara a emigrar población para ocupar los puestos de trabajo considerados impropios para la bonanza causada por dicha situación. Así, por doquier diversos sujetos se dieron a la tarea de aprovechar la efervescencia, tomando la decisión de buscar oportunidades en los países que por cuenta del remezón del modelo económico, estaban requiriendo de personal para ocupar las vacantes no atractivas o de bajo valor agregado, en las que claro está el espacio para la población femenina tendría lugar.

Por montones aparecieron foráneos para hacer suya la bonanza laboral, a veces de forma legal y muchos otras de forma ilegal o por otras vías, que al fin de cuentas no era la preocupación, porque para entonces, los requerimientos sobre dicha mano de obra, era una circunstancia que habría de cubrir por encima de cualquier desavenencia concertada por la entrada masiva de extranjeros. El fenómeno "invasivo" sirvió para que tras de ello se establecieran además de barrios de origen extranjero, la consumación de familias en el país (Garay y Rodríguez).

Ya no constituye una novedad la creciente importancia de la migración internacional en el mundo contemporáneo, pero sí puede causar sorpresa su trascendencia toda vez que muchos autores han llegado a considerarla como uno de los rasgos más sobresalientes y determinantes de la globalización en el presente siglo.

La razón que acompañaría el llamado de hacer parte de los frutos del nuevo orden económico, no había contemplado lo que podría traer consigo el flujo creciente de oriundos de diversos países, y más aun lo que con el tiempo podría significar para sus economías el encontrarse con nuevos grupos sociales, entre lo que Huntington llamaría el choque de las civilizaciones. De ahí que el tema pasó del alborotado ánimo, al de preocupación y sinsabor para quienes consideraban el proceso migratorio cómo un hecho sin regulación, y que por cuenta de ello, muchos de los logros alcanzados se verían amenazados (Aruj, 2008). 
Hoy por hoy, las soluciones difícilmente dependen de algunas acciones políticas. Los conflictos que no se resuelven y que tienden a expulsar población desde América Latina hacia el primer mundo responden fundamentalmente al modelo. El fin último es que los excluidos no molesten. Entonces, las fantasías asociadas a la migración terminan siendo funcionales a los objetivos del proyecto del modelo que nos domina. Eso es hegemonía.

De manera abierta, la percepción que hasta hace poco se tenía en mayoría con respecto al proceso de engranaje exitoso que había tenido la incursión de la población foránea en las actividades económicas. La política y la sociedad de los países receptores, sería precisamente el punto de partida para encontrar desavenencias de orden estructural que impediría registrar la inmigración como un proceso que pondría en riesgo las condiciones obtenidas por los países desarrollados. El origen y condición del inmigrante no había alcanzado a insertarse plenamente a las exigencias del mundo desarrollado, siendo estos, escenarios ya revisados (Gonzáles, 2000).

La emigración lleva consigo subyacentemente la idea del regreso, aunque luego la mayoría de las personas estén demasiado integradas en los países que los acogieron, como para que el retorno pase de ser solo una idea mítica. Sin embargo, este supuesto resurge como una alternativa muy clara cuando, en las últimas décadas, la crisis económica afecte a los países que los han acogido, sobre todo para los descendientes.

Es relevante que los territorios regionales y locales igualmente de manera firme determinen hasta dónde es su compromiso con la población migrante. Este se debe considerar como un hecho inexpugnable a cualquier espacio, y que como tal, se hace necesario discutir las condiciones o parámetros en que dicha población tendría asiento en dichas escalas, claro está con la siempre necesaria correlación con un diseño de política nacional coherente, que abarque igualmente, las condiciones de género de la inmigración (Stefoni, 2011).

Ello implica hacer parte a las migraciones de las políticas más generales de desarrollo y no traspasar a los migrantes la función de asumir las políticas públicas. Otro aspecto interesante de puntualizar es la importancia de encuadrar aquellos programas de inversión y usos de remesas, en políticas y programas de retorno más generales o bien en programas de integración de la comunidad de emigrantes en el exterior de las comunidades locales y nacionales de origen.

La respuesta ante dicho choque directo al proceso migratorio no se hizo esperar, pues los inmigrantes que con el tiempo habían comenzado adquirir condiciones con las cuales tendrían un lugar en la tendencia económica de dichos países. A su vez, que mostrarían el talante para estar acorde con las exigencias del modelo económico, político y social, pondrían a funcionar sus influencias para que cambiara la posición o por lo menos, comenzara a revisarse las circunstancias del proceso de manera mesurada y medida por los hechos; no abusiva como se ha querido presentar en temáticas tan sensibles como la sobrepoblación entre otras (Palma, 2006).

No obstante, en los últimos años (década de los noventa y principios del nuevo milenio), se ha observado que las ciudades han crecido debido a una alta tasa de 
fecundidad de sus pobladores. La inmigración en estas localidades no ha sido el principal factor de crecimiento.

Paradójicamente en extremo se registra un alto patriotismo cuando se trata de considerar el argot nacionalista por parte de los inmigrantes de distintos países, incluso superando su condición de habitante plural o regional del país al cual se deben. En este escenario la connotación de nacional supera con creces la realidad particular que incluso registró en su país natal, demostrando con ello que además de reconocer su origen, identifica claramente la importancia de elevar la connotación de origen nacional, aunque ello genere algunas dificultades (Cuero, 2011, pp. 118-119):

Cada vez que estoy en México o Brasil percibo fácilmente cómo las personas se refieren a su nacionalidad lo mismo que a sus grupos étnicos. En varias ocasiones le he preguntado a un mexicano o a un brasileño acerca de su propio grupo étnico y siempre contestan que son mexicanos o brasileros, a pesar de su verdadera apariencia étnica. Por consiguiente, esta perspectiva nacionalista no solo causa confusión, sino que también acepta el estereotipo latino euro céntrico ya impuesto.

En otro escenario, se encuentran los países beneficiarios de las actividades económicas y recursos enviados por cuenta de la población migrante en los países receptores. Para ellos, el tema no pasa más que por la retina de quien está dirigiendo o tomando las decisiones en los países denominados desarrollados, y que bajo su justa medida, tienen toda la libertad para replantear el espacio de acción de estos grupos sociales. No obstante, se percibe un vacío fuerte en cuanto lo que representa para estos países realmente la población migrante en dichos estados receptores, sobre todo en lo que concierne al manejo individualizado del tema, particularmente con respecto al género. (Ramírez y otros, 2005, p. 9): "A pesar del alcance y características de la feminización de las migraciones, la incorporación del análisis de género en el estudio de las mismas es relativamente reciente".

La falta de categorización y evaluación de variables con respecto a la migración, ha terminado por pauperizar la recursividad con que podrían presentarse alguna serie de propuestas con las cuales podría avanzarse respecto a ello. Por ahora, para los países receptores solo lo estiman como una de las causales por las cuales ciertas políticas internas no han tenido éxito, y en el caso de los emisores, apenas han comenzado a edificar elementos de trabajo para establecer las pautas con las cuales atender a esta población que eventualmente tiene indicios de retornar en grandes cantidades.

\section{ELEMENTOS DE APROXIMACIÓN AL PROCESO MIGRATORIO EN COLOMBIA}

Las cifras relacionadas con la migración hasta hace muy poco eran identificadas como datos para indicar el estado de movilidad poblacional de los colombianos en el 
mundo, más no representaba un espacio de pleno interés. Entre otros, por obedecer a la tendencia internacional de corresponder a los procesos de mejoramiento económico o de búsqueda de oportunidades para los nacionales, que independiente a su estatus, contemplan la migración como posibilidad, en tanto, desde ella pudiesen ayudar a las familias y de paso materializar las expectativas que en algún momento habían sido trazadas (Guarnizo, 2006, pp. 84-85):

Los inicios de la migración masiva se remontan a la década de los sesenta, periodo que coincide con el fin de la violencia en Colombia y el arranque de la prolongada guerra que persiste hasta hoy. Coincide, también, con la introducción de reformas significativas a las leyes estadounidenses de inmigración que, por primera vez en la historia, asignaron cuotas de inmigración a todos los países del mundo, sin distinción de raza o etnicidad. De igual forma, estas nuevas leyes autorizaron la reunificación familiar a los inmigrantes legales, mecanismo que, eventualmente, se convertiría en la forma principal de obtener una visa de residencia en Estados Unidos. La nueva situación contextual, a mediados de los sesenta, abrió las puertas de Estados Unidos a la inmigración latinoamericana, caribeña y asiática en general, mientras declinaba la inmigración europea.

El perfil del migrante en Colombia no era parte de las políticas estatales y mucho menos públicas de las administraciones territoriales, puesto que a la luz del proceso económico internacional la profundización del proceso migratorio era claramente una consecuencia de los procesos de apertura y liberación económica. Si bien, claro está por alguna circunstancia especial generaba alguna atención, la tendencia por rastrear las acciones tomadas por el proceso de migración para el país tiene antecedentes recientes, que no obstante, hacen precisamente del cúmulo de aspectos que hoy sopesan el registro obtenido (Cárdenas y Mejía, 2006).

En cuanto a la política de inmigración, el país promovió el ingreso masivo de extranjeros durante el período 1923-1956, como mecanismo para el desarrollo económico, siguiendo el ejemplo de otros países de la región. Según Naciones Unidas (1998), ante el poco éxito de estas medidas, y frente al temor de una explosión demográfica, el país optó por incorporar medidas restrictivas en la legislación. No obstante, entre 1957 y 1981, con el auspicio de la Organización Internacional para las Migraciones, Colombia firmó acuerdos para la migración selectiva de docentes y profesionales con España, Alemania, Italia y Francia. De acuerdo con el Departamento Nacional de Planeación (1994), en años más recientes, Colombia no ha emprendido acciones decisivas para el fomento de inmigración positiva para el desarrollo económico y social. Aunque el Decreto 21 de 2001, que es la norma que dicta las disposiciones sobre la expedición de visas, control y regularización de extranjeros y otros aspectos en materia de inmigración, hace mención al fomento de inmigrantes cuyas características contribuyan a solventar las "necesidades sociales, demográficas, económicas, científicas, de seguridad y demás de interés para el 
Estado colombiano", en la práctica no hay medidas encaminadas a este objetivo. En cuanto a la legislación que regula la salida de colombianos, las normas se limitan a especificar los requisitos y restricciones al momento de salir del país.

La posición del Estado colombiano siempre estuvo dirigida a estar atento a cualquier necesidad de extrema necesidad o situación que requiriese la vinculación del aparato estatal, en tanto, representación lógica de los nacionales en cualquier parte del globo. Así, consulados y embajadas constituía para entonces -La dirección que ante cualquier suceso, debían tomar los nacionales para presentar sus circunstancias ante las autoridades ubicadas, en dichos países-, establecidas para atender hechos relacionados con la estancia de los nacionales, documentados con residencia y situaciones de ilegalidad.

El grado de transversalidad que han tomado las migraciones, activa a los estados emisores, en caso de Colombia, a tener una política mucho más clara de lo que puede entenderse el proceso en medio de las disquisiciones. Ahora bien, las migraciones presentan un efecto boomerang, debido a que ha pasado de problemática o situación de soberanía para el país receptor, a un asunto de atención y solidaridad por parte de los países emisores. Al fin de cuentas se trata de nacionales que en medio de estas circunstancias requieren de la atención directa del estado emisor, para conocer las posibilidades de regresar al país. Plantea la (OIM, 2010, pp. 82-83), que dentro de los principales avances en política migratoria en Colombia están:

- El reconocimiento de los emigrados como sujetos de derecho por parte del Estado colombiano y el emprendimiento de acciones concretas para favorecerlos.

- La asignación de responsabilidades y funciones específicas, principalmente dentro del Ministerio de Relaciones Exteriores, para la formulación e implementación de las políticas migratorias.

- La definición de procedimientos y la creación de instancias interinstitucionales de coordinación relacionadas con esas políticas.

- La definición de algunos acuerdos bilaterales específicos sobre materiales de importancia para los migrantes (seguridad social, tributación, homologación de títulos y migración laboral).

- El reconocimiento del transnacionalismo dentro de las migraciones y la consideración de las posibilidades de estas para contribuir al desarrollo del país, así como la exploración de mecanismos para hacerlo.

- La inclusión del tema del retorno.

- La aprobación de la Política Integral Migratoria en el 2009.

Uno de los retos que tiene el país es la definición de un sistema de seguimiento para lograr un mejor acompañamiento de los colombianos en el exterior, en el que se incluyan no solo aquellos que han tenido la posibilidad de emigrar a países de destino con las garantías que ofrece la migración ordenada, sino también 
a aquellos que por diversas circunstancias están dentro de la irregularidad de la migración y que por lo tanto la garantía de sus derechos está limitada. Es aún largo el recorrido que Colombia tiene que hacer en fortalecer y asegurar el respeto y la garantía de los derechos de los emigrantes colombianos en los países de destino.

En cuanto a este tema, recientemente en el país fue retomado el interés por apreciar la condición de los emigrantes colombianos en el mundo. No solo las crisis abonaron a esta situación, también el orden con que se ha venido profundizando el tema a escala institucional sirvió para que en el país el curso de la población migrante tuviese de nuevo espacio en la agenda política internacional. De allí, no solo sirvió el trabajo de algunos excancilleres para avanzar en la solución de algunas problemáticas de los inmigrantes, sino el de regresar el mismo a los primeros lugares de interés del estado central con la idea igualmente de que sean conducidos a escala territorial, obteniendo como producto de ello el documento Conpes (3603):

Se somete a consideración del Consejo Nacional de Política Económica y Social (Conpes) la Política Integral Migratoria - PIM del Gobierno Nacional. La política integra los lineamientos, estrategias y acciones de intervención para los colombianos que viven en el exterior y los extranjeros que residen en el país. Se encuentra enfocado a: 1) dar un tratamiento integral a cada una de las dimensiones de desarrollo de esta población y 2) mejorar la efectividad de los instrumentos utilizados para la implementación de estrategias y programas referentes a la población migrante.

El Estado colombiano ha atendido a la población migrante y ha encauzado el orden constitucional y la legislación necesaria para que la población encuentre posibilidades de recibo y retorno en el país, a su vez que, cuente con el apoyo necesario de las instituciones del Estado que representan la misión diplomática. No obstante, la posición del tema en el interior de los territorios, departamentos y municipios está aún por fuera del alcance de los administradores públicos territoriales, en cuyo vacío ha servido la fuerza de los argumentos para sopesar ampliamente la entrada de políticas públicas migratorias (tabla 2).

En esa medida puede debilitar las condiciones estamentales e institucionales por lo que al respecto puede representar, en un estado que si bien lo ha considerado y establecido en el marco ley, no cuenta con los elementos para advertir extensamente los episodios que puede generar el planteamiento errático de políticas estatales y, claro está, de la atención que en el frente territorial puede arrojar localmente, de no establecerse las políticas públicas pertinentes. 


\section{Tabla 2. Migración en Colombia}

Inmigrantes: Según el Censo de 2005, el número total de inmigrantes en Colombia era de 109.971 personas procedentes de diversos países y de todos los continentes. De este total $56.889(51,7 \%)$ eran hombres y $53.082(48,3 \%)$ eran mujeres.

Emigrantes estimados por quinquenio 1970-2005

\begin{tabular}{|cc|}
\hline Quinquenio & Emigrantes \\
$1970-1975$ & 179.891 \\
$1975-1980$ & 262.201 \\
$1980-1985$ & 377.755 \\
$1985-1990$ & 547.563 \\
$1990-1995$ & 786.880 \\
$1995-2000$ & 994.993 \\
$2000-2005$ & 883.420 \\
\hline
\end{tabular}

Fuente: Tomado de OIM (2010). Perfil migratorio de Colombia. Organización Internacional para las Migraciones.

A pesar de las contravenciones que al respecto se están articulando en Europa y Estados Unidos, en especial este último, para desanimar el ímpetu migratorio, reproduciendo normas similares en cuanto al trato que debe tener está población. Se insiste que la regularización no como normalización, sino como proceso de ajuste y reconocimiento, puede ser de gran utilidad para los estados emisores y receptores de la población migrante. Para ello, es necesario que claramente se dispongan de los esfuerzos y recursos necesarios para que la población, independiente a su estatus, encuentre en los mecanismos de regularización establecidos una manera no solo de institucionalizar su paso en el país receptor, sino porque no para replantear su posición frente a las posibilidades presentes y futuras.

Independiente a la posición dura y consensuada que vienen orquestando unos países más que otros, lo que es cierto, es que el tema del retorno está tomando relevancia en ambos extremos de los emisores y receptores. Razón por demás, porque todos deben estar atentos de los resultados masivos y marginales que una situación de estas pudiese provocar. No solo es el impacto de carácter económico y presupuestal que puede traer consigo dicha reinstalación de la población migrante, sino el amparo, capacidad institucional y posibilidades de los diferentes sujetos para poder apreciar y reinsertar dicha población en sus países de origen, y conocer qué tanto hay de cierto, sobre el equilibrio que de manera anhelada esperan los países de desarrollo que dicha situación arrojase. Agrega (Martínez, 2003, p. 37):

En general, las experiencias de retorno denotan diversas dificultades tanto para las personas afectadas y sus comunidades como para los países que enfrentan los procesos de reinstalación. Un caso ilustrativo es el retorno de personas indocumentadas que, en la visión de la Organización Internacional 
para las Migraciones (OIM), constituye uno de los principales desafíos para la comunidad internacional, dada la enorme dificultad de asegurar la protección y el bienestar de las personas involucradas. Esta organización cuenta con un Servicio de Retorno Asistido para el regreso voluntario de indocumentados y refugiados, así como para personas deportadas, solicitantes de asilo, personas tratadas, estudiantes, trabajadores y personal calificado.

De estas experiencias trazadas se tendrá que aprehender demasiado, pues en razón de los elementos e informaciones consideradas, son estos departamentos los primeros en afrontar el estado de desbalance que provocaría la llegada masiva de migrantes, pues si bien, hoy son parte de la economía nacional real al enviar recursos de divisa, lo que no está claro aún, es el estado de capacidad que tiene el Estado central colombiano y los territoriales para responder a las demandas de esta población en materia de garantía económica y social. Si bien, no sería de manera absoluta para todos igual, si se requerirían respuestas concretas al respecto, más allá de la disposición de la ley, de ahí, la necesidad de programación de políticas públicas relacionadas con el campo de las migraciones.

\section{CONCLUSIONES}

La atención sobre el tema de migraciones tuvo respuesta en la redimensión del programa de las Naciones Unidas para las Migraciones (OIM), y en atención a ello, la caracterización que por cuenta de los países debía hacerse, tanto para los países emisores como receptores de migrantes, para que dicha población se acogiera desde diferentes perspectivas, entre las que se contaría, claro está, el aporte dado a sus países de origen y en los países en donde terminarían asentándose en diferentes posiciones, en los que el tema central, como el lugar ocupado por ellos, pasarían a ser parte de la política internacional de las naciones a escala general, dentro de los que estaría construyéndose un análisis en el caso colombiano (Garay y Medina, 2003).

El éxodo de colombianos al exterior desde finales de los noventa, a diferencia de migraciones previas, abarca un espectro más amplio de trabajadores, que incluye obreros cualificados, profesionales especializados y empresarios. Asimismo, se caracteriza por tratarse de una alta proporción de migrantes en edad productiva, que se concentra en una franja de edad entre los 25 y 50 años (Banco de la República, 2003).

La migración debe pasar de la discusión estatal multilateral hacia la programación pública territorial de los países que en principio han tenido gran ascendencia migratoria. Por ende, la necesidad de plantear el debate con respecto a la calidad y condiciones de los ciudadanos inmigrantes o de los que comienzan el ciclo para acercarse a dicha posibilidad. Para ello, se aspira a concentrar el debate hacia la realidad nacional y no un hecho pasajero. 
La ausencia y consolidación de políticas públicas por parte de los países, origen de los inmigrantes, y la salvedad que hacen de su componente como un importante rubro para la economía, representa para todos, el indicio de que en términos reales la población migrante solo representa un eslabonamiento económico por parte de quien adquiere la población inmigrante. De cierta manera, pierde no solo su condición ciudadana o nacional en el país receptor, a su vez que en su propio país de origen.

El balance obtenido con dicho proceso es que con el derrumbe de las economías y el malestar global con el modelo de apertura y libertad plena, aquellas querellas que en un comienzo fueron tildadas de fanatismo y xenofobia, hoy son la base para auspiciar una discusión amplia y seria en los países desarrollados, paradójicamente, no en los países que han producido un número importante de inmigrantes, llevando el tema a discusión nacional. Además que por cuenta del tema de seguridad, terminó siendo convertido en el culpable de todos los males que hoy se presentan al modelo económico, cuando en realidad la propia migración es una consecuencia.

De ambos lados, la mirada se ha anquilosado y tomado visos de polarización, sobre el que entidades y organismos internacionales como la Organización Internacional para las Migraciones - OIM han puesto el tema a consideración a la par con la Organización de las Naciones Unidas - ONU. Para quienes si bien la migración es un fenómeno provocado por el activismo económico o por las ventajas económicas de la liberación económica. Este debe ser abordado como un proceso de transformación demográfica que gestiona los Estados receptores, en el marco de una política pública internacional de emigraciones, auspiciado y apoyado de manera limitada, pues hasta ahora, aún no se conoce el estado de cuestión amplia, para que un bando u otro tome acciones, a partir de observancias particulares.

La necesidad de diseñar una política pública de migraciones, tanto de países receptor como emisario, determina la capacidad de gestión internacional que tienen las autoridades internacionales, para internalizar los hechos que directamente modifican el quehacer interno en que se atienden las agendas políticas y públicas. Para ello, es importante iniciar un proceso de diálogo y revisión de las circunstancias que representan para las localidades, regiones-territorios y países, el contener o disponer de población migrante, en aras de convalidar el esfuerzo de dicha población en otras latitudes, pero asimismo entregar un estado de balance de lo que puede significar una política pública que claramente atienda esta población, en el ámbito nacional como el internacional.

Es importante resaltar que la necesidad estriba en avanzar en los aspectos hasta ahora contemplados y vinculados con la migración. De ahí, que sea urgente animar la discusión, por lo que representa para Colombia un tema, que en términos de relevancia para la elaboración de los planes y la misma apuesta de las agendas estratégicas para el desarrollo. No pueden dejar pasar de largo la posibilidad de diálogo con la población migrante que retorna, la cual puede ofrecer interesantes perspectivas para la vinculación subregional y territorial de las diferentes regiones del país, en aras de fomentar el espacio de las relaciones internacionales en diversos escenarios. 


\section{REFERENCIAS}

Aruj, R. (2008). Causas, consecuencias, efectos e impacto de las migraciones en Latinoamérica. Papeles de población. México: Universidad Autónoma del Estado de México.

Azagra, J. (2010). Las migraciones internacionales y su incidencia en origen y destino. En De las migraciones como problema a las migraciones como oportunidad. Codesarrollo y movimientos migratorios. Madrid.

Banco de la República. (2003). Editorial. Revista del Banco de la República, 910.

Cárdenas, M., y Mejía, C. (2006). Migraciones internacionales en Colombia: ¿qué sabemos? Documentos de Trabajo, $N^{\circ} 30,1-50$. (Working papers series).

Cuero, R. (2011). De Buenaventura a la Nasa. Bogotá.

Departamento Nacional de Planeación. (2009). Política integral migratoria. Documento CONPES 3603, 1-96. Bogotá.

Kleiner-Liebau, D. (2006). ¿Integración omarginación? Conflicto sociale inmigración enAlemania.2006.Recuperadodehttp://pendientedemigracion.ucm.es/info/gemi/ descargas/libros/3CACHONConflictoseinmigraExperienciaseuropeas2008.pdf (último acceso: 13 de junio de 2015)

Garay, L., y Rodríguez, A. (2005). Estudio sobre migración internacional y remesas ( $1^{\mathrm{a}}$ ed.). Bogotá: OIM y Ministerio de Relaciones Exteriores de Colombia.

Garay, L., y Medina, C. (2003). La migración colombiana a España. El capitulo más reciente de una historia compartida. Madrid: Ministerio de Trabajo e Inmigración Secretaría de Estado de Inmigración y Emigración.

Gómez, M., Albarran, I., Malgesini, G., y El Harchi, Y. (2010). Migraciones y codesarrollo en la relación entre la Unión Europea y América Latina y El Caribe. http://www.cideal.org/docs/Migraciones\%20y\%20codesarrollo_UE_ ALA_Caribe.pdf (último acceso: 24 de junio de 2015)

González, E. (2000). Los latinoamericanos que llegan. Balance y estrategias de un colectivo inmigrante en la España del fin del milenio. Revista de Indias, $L X$, núm. 219, 547-563.

Guarnizo, L. (2006). El Estado y la migración global colombiana. Migración y desarrollo. Migración y Desarrollo, 6, 79-101.

Khoudour, D. (2007). ¿Por qué emigran los colombianos? Un análisis departamental basado en el Censo de 2005. Revista de Economía Institucional, vol. 9, 255-271.

Martínez, J. (2003). El mapa migratorio de América Latina y el Caribe, las mujeres y el género. Santiago de Chile: CEPAL.

Mora, A. (2010). Inmigración, participación e integración ciudadana: hacia una nueva configuración de la ciudadanía. En Derechos humanos, migraciones y diversidad. Valencia: Tirant Lo Blanch.

Organización de Estados Americanos - OEA. (2011). Migración internacional en las Américas: Primer informe del Sistema Continuo de Reportes de Migración 
Internacional en las Américas. Washington, D.C.: OEA - Organización de Estados Americanos.

Internacional para las Migraciones - OIM. (2010). Perfil migratorio de Colombia. Bogotá: Fondo Editorial Ministerio de Relaciones Exteriores.

Internacional para las Migraciones - OIM. (2006). La migración internacional y el desarrollo. Perspectivas y experiencias de la organización internacional para las migraciones. Bogotá: Fondo Editorial Ministerio de Relaciones Exteriores.

Palma, S. (2006). Migración en la época de post-conflicto: Vulneración de derechos de las poblaciones excluidas e impacto sobre la participación política. Guatemala: Consejería en Proyectos.

Pesantez, B. (2006). Las redes familiares en el proceso migratorio de los ecuatorianos a España. Revista Alternativas. Cuadernos de Trabajo Social, 14, 15-34. Universidad de Alicante.

Ramírez, C., García, M., y Míguez, J. (2005). Cruzando fronteras: Remesas, género y desarrollo. Santo Domingo: Instituto Internacional de Investigación y Capacitación de las Naciones Unidas Para la Promoción de la Mujer.

Rodríguez, M. (2008). El fenómeno de las migraciones internacionales: Una perspectiva de estudio desde la psicología social y los valores culturales. Universidad Complutense de Madrid. Recuperado de http://eprints.ucm. es/8057/2/T30385.pdf (último acceso, 27 de junio de 2015).

Santos, M. (2009). Migraciones, sostenibilidad y educación. Revista de Educación, Número extraordinario, 123-145. Santiago de Compostela: Universidad Santiago de Compostela,

Solanes, Á. (2002). Inmigración y derecho humanos. Mediterráneo Económico, 1, 103-118. Instituto de Estudios de Cajamar.

Sprandel, M., Rocha, R., y Fusco, W. (2008). Las migraciones internacionales en las Américas. Recuperado de http://www.iscod.org/Publicaciones/ migra\%C3\%A7\%C3\%B5es_completo.pdf trabajoysociedad (último acceso: 30 de junio de 2015).

Stefoni, C. (2011). Migración, remesas y desarrollo. Estado del arte de la discusión y perspectivas. Polis Dimensión de lo público. Sociedad y Estado, 30, 1-26.

Velasco, J. (2006). Mutaciones de la ciudadanía en el contexto de las migraciones transnacionales. Recuperado de http://www.uv.es/cefd/14/velasco.pdf (último acceso: 30 de junio de 2015). 